\title{
Seroprevalence and molecular characteristics of varicella-zoster virus infection in Chinese children
}

Lin Luan ${ }^{1+}$, Xiaochen Shen ${ }^{2+}$, Jing Qiü ${ }^{3,4+}$, Yang Jing ${ }^{3}$, Jingqi Zhang ${ }^{3}$, Jie Wang ${ }^{3}$, Jun Zhang ${ }^{1 *}$ and Chen Dong ${ }^{3 *}$

\begin{abstract}
Background: Varicella-zoster virus (VZV) infection in children is an important public health problem in China. We performed the current study to explore the seroprevalence of VZV infection in Chinese children in order to provide more information for improvement of varicella vaccination in China.

Methods: Three thousand fourteen children were recruited from Chinese kindergarten students aged from four to six years. Anti-VZV IgG and IgM were assayed using enzyme-linked immunosorbent assay. Both ORF22 and ORF62 of VZV were amplified, sequenced, and analyzed by nested PCR.

Results: Among 3014 children, $43.9 \%$ of boys and $46.3 \%$ of girls were vaccinated with varicella vaccine, respectively. The seroprevalence of anti-VZV IgG was 54.4\% in the children with varicella vaccination, which was significantly higher than those in unvaccinated children (49.2\%) $\left(X^{2}=8.206, P=0.004\right)$. Among of the vaccinated children, the detection rates of VZV IgG antibody increased with age, with 49.4, 50.9 and 58.9\% in 4, 5 and 6-year groups, respectively (Trend $X^{2}=17.202, P=0.002$ ). However, there was no difference in anti-VZV IgG detection rates among those unvaccinated children in different age groups (Trend $X^{2}=8.681, P=0.070$ ). In addition, 13 boys and 13 girls were positive for anti-VZV IgM, respectively. Among of them, eight children (0.6\%) have received varicella vaccination, which was similar to those in unvaccinated children (1.1\%). However, only one ORF22 sequence was isolated from an unvaccinated 5-year boy. Compared to the reference VZV sequences, the nucleotide homology was estimated to be $99.7 \%$ with genotype $J$.

Conclusions: Our study indicated that about half of Chinese children aged four to six years have a high risk of VZV infection. It should be helpful for the evaluation on the necessity of varicella immunization in China.
\end{abstract}

Keywords: Varicella-zoster virus, Seroprevalence, vaccination, Genotype

\section{Background}

Varicella-zoster virus (VZV), a member of the family Herpesviridae and the subfamily Alphaherpesvirinae, is usually transmitted by airborne droplets or close personal contact [1-3]. The primary VZV infection mainly occurs in childhood and causes varicella (chickenpox), which has generally mild and easily diagnosed syndromes. However, an estimated $2-6 \%$ of varicella cases can develop

\footnotetext{
*Correspondence: sz_zhangj@163.com; cdong@suda.edu.cn

${ }^{\dagger}$ Lin Luan, Xiaochen Shen and Jing Qiu contributed equally to this work.

${ }^{1}$ Suzhou Center for Disease Control and Prevention, 72 Sanxiang Road,

Suzhou 215000, China

${ }^{3}$ Department of Epidemiology and Statistics, School of Public Health, Jiangsu

Key Laboratory and Translational Medicine for Geriatric Disease, Medical

College of Soochow University, 199 Renai Road, Suzhou 215123, Jiangsu,

China

Full list of author information is available at the end of the article
}

complications including bacterial superinfections as well as neurologic or pulmonary disorders $[4,5]$. Following primary infection, the virus may become latent in the dorsal root ganglia, cranial nerve ganglia or autonomic ganglia and can reactivate, causing herpes zoster (HZ) or 'shingles', which typically occurs in people aged more than 50 years [6-8].

Safe and effective live, attenuated varicella vaccine was developed in 1974, which was produced by a seed virus isolated from a Japanese boy (named OKA) with typical varicella. Before the introduction of varicella vaccine, the disease was very common worldwide $[9,10]$. With increasing vaccine coverage in the countries that implemented universal varicella vaccination for children, the incidence of varicella significantly decreased by $80-85 \%$

(C) The Author(s). 2019 Open Access This article is distributed under the terms of the Creative Commons Attribution 4.0 International License (http://creativecommons.org/licenses/by/4.0/), which permits unrestricted use, distribution, and 
after a single dose and by $98-99 \%$ after a second vaccine dose compared with the pre-vaccination era, respectively [11]. Moreover, varicella-related hospitalization and mortality rates dramatically decreased by $75-88 \%$ and $88-97 \%$ after a single dose of vaccine, respectively [12]. Despite that varicella vaccine is recommended by the World Health Organization (WHO) and is available throughout the world, it has only been incorporated into the national immunization program for children in a small number of countries because it is relatively expensive for the developing regions [13].

VZV infection is an important public health problem in China. More than $90 \%$ of varicella cases have been reported in the children aged less than 15 years [14, 15], and about $5 \%$ of these cases develop severe complications [16], especially in kindergarten children. Although several Chinese epidemiological surveys have suggested that varicella vaccination could decrease the disease burden, the vaccine is not mandatory for children to date [11, 17-19]. In order to provide additional information for improvement of varicella vaccination strategies in China, we performed the current population-based study to analyze the seroprevalence of VZV infection in Chinese kindergarten children with or without varicella vaccination.

\section{Methods}

\section{Study population and sample collection}

Between August 2017 and September 2017, 3014 kindergarten students aged 4-6 years in Suzhou Industrial Park (Jiangsu, China) were invited to participate in the present study when they received an annual physical examination. Written informed consents were obtained from the parents of children after declaring the aims of the present study. A blood sample $(5 \mathrm{~mL})$ was taken from 3003 children because 11 children did not agree to provide their blood samples. The samples were immediately spun down and the serum was stored at $-40^{\circ} \mathrm{C}$ for later analysis. Varicella vaccination information including the date of administration and trademark of vaccine was retrieved from the Immunization Registry System or the detailed vaccination records. The study protocol was approved by the ethics committees of Suzhou Centers for Disease Control and Prevention in accordance with the ethical guidelines of the 1975 Declaration of Helsinki.

\section{Serological assessments}

The serum samples obtained from all children were tested for anti-VZV IgG and IgM antibody by enzyme-linked immunosorbent assay (ELISA) with the commercial kits of "Diagnostic Kit for IgG Antibody to Varicella-Zooster Virus" and"Diagnostic Kit for IgM Antibody to VaricellaZooster Virus" (Beier Biotechnology, Beijing, China), respectively. The cut-off value was calculated for each plate according to the manufacturer's instructions. When an ambiguous result was found, the sample was retested and confirmed as positive only if one of the repeats $(2 / 3$ of the total tests) was positive. According to the manufacture's introductions, both sensitivity and specificity of IgG method and IgM method were more than 98\%, and the $\mathrm{CV} \%$ of two methods were less than $15 \%$.

\section{VZV DNA isolation and sequence analysis}

VZV DNA was extracted by Viral RNA/DNA Extraction Kit Version 5.0 (TaKaRa Biotechnology, Dalian, China) from $300 \mu \mathrm{L}$ of serum. According to the previous reports [20, 21], a 359-bp region of the ORF22 gene (nt37870-nt38228, reference strain Dumas, XO4370) and a 419-bp region of ORF62 gene (nt106983-nt107401, reference strain Dumas, XO4370) were amplified by polymerase chain reaction (PCR). The primers used for ORF22 were ORF 22F: 5'-TAGC ATGTCTGGAGGCAATGG and 22R: 5'-GGCCTTGGA AACCACATGATCG; and the primers used for ORF62 were ORF 62F: 5' - GGCCTTGGAAACCACATGATCG and 62R: 5' - CGTCTCCCGTTCCGCATGTAG. The PCR products were purified and sequenced using the ABI 3730 (Applied Bio systems, Foster City, USA). The genotype of isolated VZV strain was identified using phylogenetic analysis by the neighbor-joining algorithm in MEGA version 4.1 software. The reliability of the phylogenetic analysis was tested by bootstrap analysis with 1,000 replicates. VZV reference wildtype sequences of genotype E strains included Dumas, BC (AY548171) and SD (DQ479953), genotypes E2 strains included HJO (AJ871403) and 11 (DQ479955), genotype M1 strain CA123 (DQ457052), genotype M2 strains included DR (DQ452050) and 8 (DQ479960), and genotype J strains included pOka (AB097933), pOka-derived vaccine strain (vOka; AB097932), VariVax (DQ008355) and Varilrix (DQ008354) were used to identify nucleotide variability.

\section{Statistical analysis}

Statistical analysis was performed using SAS version 9.2 software (SAS Institute Inc., Cary, USA). The seroprevalence of anti-VZV IgG antibody between different groups were compared using the $\chi^{2}$ test or trends $\chi^{2}$ test. All tests were two sided, and differences were considered statistically significant if $P<005$.

\section{Results}

Vaccination characteristics of studied Chinese children

Among 3014 children, 701 boys (43.9\%) and 656 girls (46.3\%) were vaccinated with Vari-L varicella vaccine (Changchun Institute of Biology Products, Changchun, China), respectively, and only 21 children received the second vaccine dose. The mean ages of the first and the second dose of vaccine were $5.20 \pm 0.83$ and $5.71 \pm 0.46$ years, respectively. A total of $33.7,45.6$ and $53.6 \%$ of children were vaccinated in the 4,5 and 6-year groups, respectively (Trend $X^{2}=81.678, P=0.000$, Table 1 ). 
Table 1 Characteristics of varicella vaccination among Chinese Children aged 4 to 6 years

\begin{tabular}{cllll}
\hline & $\begin{array}{l}\text { Varicella vaccinated } \\
(\%)\end{array}$ & $\begin{array}{l}\text { Varicella unvaccinated } \\
(\%)\end{array}$ & $x^{2}$ & $P$ \\
\hline Total & & $896(56.1)$ & 1.747 & 0.187 \\
Boys & $701(43.9)$ & $761(50.2)$ & & \\
Girls & $656(49.8)$ & & & \\
4 years & & $342(67.7)$ & 0.922 & 0.337 \\
Boys & $163(32.3)$ & $267(64.5)$ & & \\
Girls & $147(35.5)$ & & & \\
5 years & & $275(56.6)$ & & \\
Boys & $211(43.4)$ & $241(52.2)$ & & \\
Girls & $221(47.8)$ & & 0.193 \\
6 years & & $279(46.0)$ & & \\
Boys & $327(54.0)$ & $253(46.8)$ & & \\
Girls & $288(53.2)$ & & & \\
Trend $x^{2}=81.678, P=0.000$ & & & \\
\hline
\end{tabular}

Among of them, 137 (10.1\%), 699 (51.5\%), 331 (24.4\%), 118 (8.7\%), 29 (2.1\%), 26 (1.9\%) and 17 (1.3\%) children were administered with the first dose of vaccine at $<1$, $1-2,2-3,3-4,4-5,5-6$ and $\geq 6$ years of age, respectively (Fig.1).

\section{Seroprevalence of anti-VZV IgG among studied children}

In the present study, ELISA was performed on the serum samples of the 3003 participants ( 1592 boys and 1411 girls). As the results shown, 837 boys $(52.6 \%)$ and 710 girls $(50.3 \%)$ were positive for anti-VZV IgG, respectively $\left(X^{2}=1.776, P=0.411\right)$. The seropositivity of VZV IgG increased with age, which was detected in
47.6, 49.2 and $55.5 \%$ of the children in 4, 5 and 6-year groups, respectively (Trend $x^{2}=27.071, P=0.000$ ).

Among of 1357 children with varicella vaccination, the seroprevalence of anti-VZV IgG was $54.4 \%$, which was significantly higher than those in unvaccinated children (49.2\%) $\left(x^{2}=8.206, P=0.004\right.$. Table 2). Additionally, among of the vaccinated children, the detection rates of VZV IgG antibody increased with age, with 49.4, 50.9 and $58.9 \%$ in 4,5 and 6-year groups, respectively (Trend $X^{2}=$ 17.202, $P=0.002)$. However, there was no difference in anti-VZV IgG detection rates among unvaccinated children, with $46.7,49.4$ and $51.7 \%$ in 4 years, 5 years and 6 year groups, respectively (Trend $x^{2}=8.681, P=0.070$ ) (Table 2).

The results from subgroup analysis showed that among vaccinated children, the seroprevalence of antiVZV IgG in 5 years old boys was significantly higher than those in 5 years old girls $\left(55.0 \%\right.$ vs $48.1 \%, X^{2}=$ 6.823, $P=0.033$ ). However, no difference in VZV IgG antibody seropositivity was detected between unvaccinated boys and girls with 5 years of age. Additionally, no significant difference in anti-VZV IgG detection rates was detected between boys and girls in 4- and 6-year groups regardless of vaccination status (Table 3 ).

\section{Seroprevalence of anti-VZV IgM among studied children}

Twenty-six children (13 boys and 13 girls) were positive for anti-VZV IgM. Among of them, eight childrenhave received varicella vaccination, which was similar to those in unvaccinated children $\left(0.6 \%\right.$ vs $\left.1.1 \%, X^{2}=2.153, P=0.142\right)$. Additionally, the seropositivity of anti-VZV IgM was 0.5 , 1.1 and $1.0 \%$ in 4,5 and 6-year groups. There was no

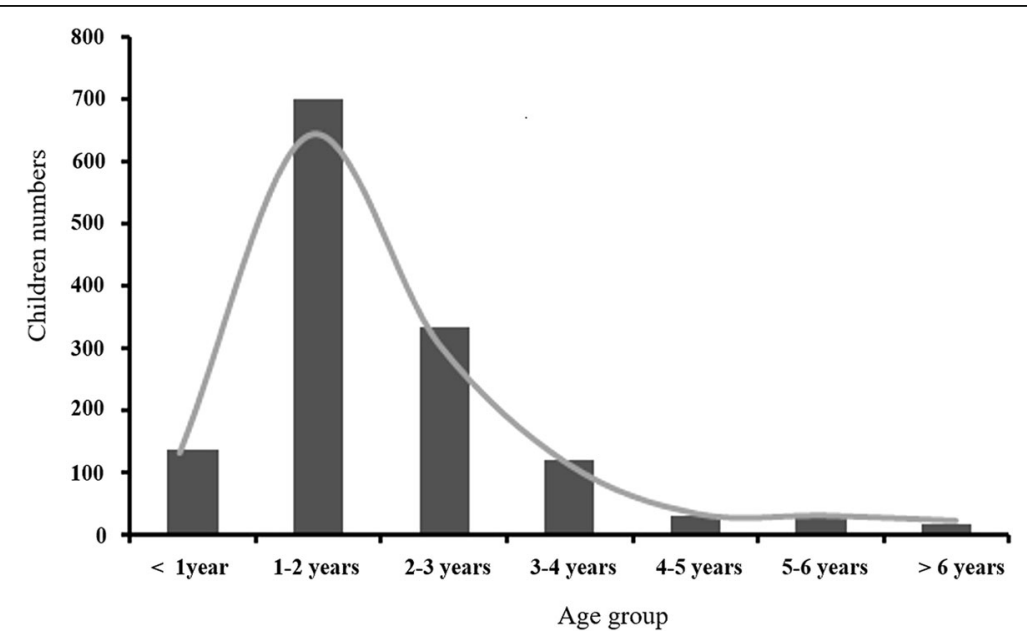

Fig. 1 The age distribution of the Chinese children administered with the first dose of varicella vaccine. The bars represented the number of the children with the first dose of varicella vaccine in different age groups. The lines showed the trend of the age distribution of the children with the first dose of varicella vaccination 
Table 2 Seroprevalence of anti-VZV IgG antibody among vaccinated and unvaccinated children aged 4 to 6 years

\begin{tabular}{|c|c|c|c|c|c|c|}
\hline \multicolumn{3}{|c|}{ Vaccinated } & \multicolumn{2}{|c|}{ Unvaccinated } & \multirow[t]{2}{*}{$x^{2}$} & \multirow[t]{2}{*}{$P$} \\
\hline & $\begin{array}{l}\text { IgG } \\
\text { Positive (\%) }\end{array}$ & $\begin{array}{l}\text { IgG } \\
\text { Negative (\%) }\end{array}$ & $\begin{array}{l}\text { IgG } \\
\text { Positive (\%) }\end{array}$ & $\begin{array}{l}\text { IgG } \\
\text { Negative (\%) }\end{array}$ & & \\
\hline Total & $735(54.4)$ & $616(45.6)$ & $812(49.2)$ & $840(50.8)$ & 8.206 & 0.004 \\
\hline 4 years & $153(49.4)$ & $156(50.6)$ & $284(46.7)$ & $324(53.3)$ & 0.538 & 0.463 \\
\hline 5 years & $220(50.9)$ & $207(49.1)$ & $253(49.4)$ & $259(50.6 \%)$ & 0.334 & 0.563 \\
\hline 6 years & $362(58.9)$ & $253(41.1)$ & $275(51.7)$ & $257(48.3)$ & 5.652 & 0.017 \\
\hline \multicolumn{3}{|c|}{ Trend $x^{2}=17.202, P=0.002$} & \multicolumn{2}{|c|}{ Trend $X^{2}=8.681, P=0.070$} & & \\
\hline
\end{tabular}

significant difference in the detection rates of VZV IgM antibody among three groups (Trend $\chi^{2}=1.625, P=0.444$ ).

\section{Analysis of VZV DNA amplified from children}

Twenty-six anti-VZV-IgM-positive samples were further analyzed to determine the existence of VZV DNA by amplification of 359-bp ORF22 sequence and 419-bp ORF62 sequence, respectively. However, only one ORF22 sequence was obtained from an unvaccinated 5year boy. Compared to the reference VZV sequences, the nucleotide homology was estimated to be $99.7 \%$ with genotype J, but only 98.6, 98.6, 98.9 and $99.4 \%$ similar to the genotype E, E2, M1 and M2 VZV strains, respectively. Therefore, this VZV isolate, named Soochow_VZV (GenBank no. MK047349) was classified as genotype J (Fig. 2), which was widely distributed in eastern China.

\section{Discussion}

This study was conducted to analyze the seroprevalence of VZV infection in children with the aim to provide additional data for the evaluation of universal varicella vaccination program in China. As expected, the results showed that the seropositivity of anti-VZV IgG in vaccinated children was significantly higher than those in unvaccinated children. Moreover, the seroprevalence of anti-VZV IgG increased with age among vaccinated children $(49.4 \%$ in age $4,50.9 \%$ in age 5 and $58.9 \%$ in age 6$)$. Previous results from a Korean study reported that the anti-VZV IgG seropositivity was $49 \%$ in age $4,62 \%$ in age 5 and $70 \%$ in age 6 , respectively [22]. The detection rate of VZV IgG antibody in Chinese vaccinated children was obviously lower than those in Korean vaccinated children. Considering that Korea has already incorporated varicella vaccine in the National Immunization Program, more scientific vaccination program is needed to be established and recommended to the children in China.

Among unvaccinated children, more than half of them were anti-VZV IgG negative. No significant difference in anti-VZV IgG seropositivity was detected among the 4, 5 and 6-year groups and between boys and girls. These results indicated that more than half of the children had a high risk of VZV infection. Therefore, the varicella vaccination coverage should be broadened in China. Although the varicella vaccine is a live, attenuated vaccine, several studies have indicated that a second dose of the vaccine would provide higher antibody levels [23-25]. Moreover, the

Table 3 Subgroup analysis of anti-VZV IgG antibody among vaccinated and unvaccinated children aged 4 to 6 years

\begin{tabular}{|c|c|c|c|c|c|c|c|c|}
\hline & \multicolumn{2}{|l|}{ Vaccinated } & \multirow[t]{2}{*}{$x^{2}$} & \multirow[t]{2}{*}{$P$} & \multicolumn{2}{|c|}{ Unvaccinated } & \multirow[t]{2}{*}{$x^{2}$} & \multirow[t]{2}{*}{$P$} \\
\hline & $\begin{array}{l}\text { IgG } \\
\text { Positive (\%) }\end{array}$ & $\begin{array}{l}\text { IgG } \\
\text { Negative (\%) }\end{array}$ & & & $\begin{array}{l}\text { IgG } \\
\text { Positive (\%) }\end{array}$ & $\begin{array}{l}\lg G \\
\text { Negative (\%) }\end{array}$ & & \\
\hline \multicolumn{9}{|l|}{ Total } \\
\hline Boys & 387 (55.3) & $313(44.7)$ & 3.410 & 0.182 & $450(50.4)$ & 442 (49.6) & 1.303 & 0.257 \\
\hline Girls & $348(53.5)$ & $303(46.5)$ & & & $362(47.6)$ & 398 (52.4) & & \\
\hline \multicolumn{9}{|l|}{4 years } \\
\hline Boys & $78(48.1)$ & 84 (51.9\%) & 1.159 & 0.560 & $166(48.5)$ & $176(51.5)$ & 1.137 & 0.289 \\
\hline Girls & 75 (51.0) & $72(49.0)$ & & & $118(44.2)$ & 149 (55.8) & & \\
\hline \multicolumn{9}{|l|}{5 years } \\
\hline Boys & $116(55.0)$ & $95(45.0)$ & 6.823 & 0.033 & $133(48.9)$ & $139(51.1)$ & 0.825 & 0.662 \\
\hline Girls & $104(48.1)$ & $112(51.9)$ & & & $120(50.0)$ & $120(50.0)$ & & \\
\hline \multicolumn{9}{|l|}{6 years } \\
\hline Boys & $193(59.0)$ & $134(41.0)$ & 0.007 & 0.935 & $151(54.1)$ & $128(45.9)$ & 1.387 & 0.259 \\
\hline Girls & $169(58.7)$ & $119(41.3)$ & & & $124(49.0)$ & $129(51.0)$ & & \\
\hline
\end{tabular}




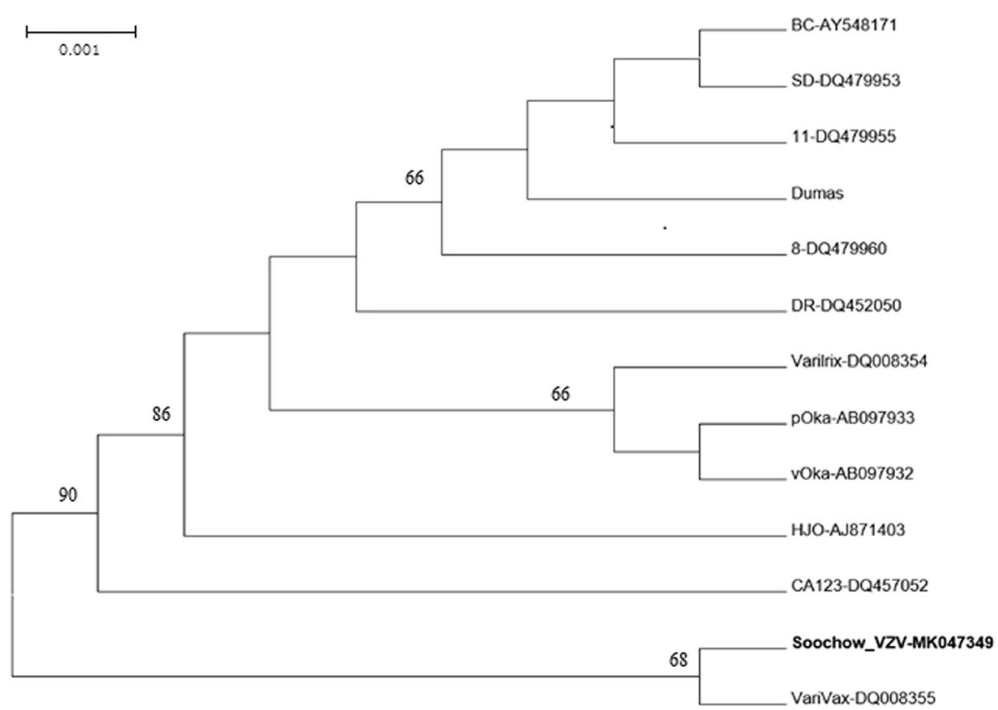

Fig. 2 Phylogenetic analysis based on nucleotide sequencing of the 359 bp ((nt37870-nt38228) of ORF22 region. The strain Soochow_VZV of genotype J was isolated from the present study. VZV reference wild-type sequences of genotype E strains included Dumas, BC (AY548171) and SD (DQ479953), genotypes E2 strains included HJO (AJ871403) and 11 (DQ479955), genotype M1 strain CA123 (DQ457052), genotype M2 strains included DR (DQ452050) and 8 (DQ479960), and genotype J strains included pOka (AB097933), pOka-derived vaccine strain (vOka; AB097932), VariVax (DQ008355) and Varilrix (DQ008354) were used to identify nucleotide variability. Percent bootstrap support (values >65\%) was indicated at the respective nodes

Advisory Committee on Immunization Practice and German Standing Committee on Vaccination have recommended a second dose varicella vaccine because of the waning of immunity. Therefore, varicella vaccine can be recommended to the children even they have been infected by VZV or administered with the first dose of vaccine before.

VZV genotypes demonstrate a specific geographical distribution. Genotypes E1 and E2 are dominant in Europe [20]. Genotype M (including M1, M2, M3 and M4) is mainly detected in tropical regions in Africa and Central America [26, 27]. Genotype J is the most prevalent VZV in the east Asia [28]. In the present study, one genotype J VZV strain was detected from 26 samples with anti-VZV IgM positive. Similar to the present findings, Sun et al. identified the 69 VZV strains from clinical patients between May 2011 and June 2013 in eastern China as genotype J [29]. Therefore, our results and previous findings suggested that the current varicella vaccine is suitable for regular use in China because the vaccine strain (Oka strain) belongs to genotype J.

However, our study has certain limitations. First, the samples were collected from a single eastern Chinese city of Suzhou, and thus might not represent the whole China. Second, because of the low virus titers, the VZV strain isolated from this study was genotyped only based on ORF22 fragment but not whole genome or restriction fragment length polymorphisms. Last, our crosssectional study just analyzed the seroprevalence data about VZV infection. Long-term follow-up studies should be performed on the high-risk children who are need vaccination.

\section{Conclusions}

Our present study revealed that about half of children aged four to six years have a high risk of VZV infection in China. As such, varicella immunization is needed to prevent virus infection and transmission.

\section{Abbreviations}

ELISA: Enzyme-linked immunosorbent assay; PCR: Polymerase chain reaction; VZV: Varicella-zoster virus

\section{Acknowledgements}

The authors thank to Lingyan Zhang, Yisun Fan and Dongliang Chen for their assistance with the sample collection.

\section{Authors' contributions}

$L L, J Z$ and $C D$ were responsible for conducting the study, literature search, and drafting of the article. $X S, J Q$ and $Y J$ were responsible for performing the ELISA and PCR testing. JZ was responsible for samples preparation. JQ and JW were responsible for data analysis. All authors contributed to the final draft and approved the final manuscript.

\section{Funding}

This study was supported by the Young Medical Talents Program of Jiangsu Province of China (QNRC2016230). The funding body did not play any part in the study design; the collection, analysis, and interpretation of data and in writing the manuscript.

\section{Availability of data and materials}

The datasets generated during and/or analyzed during the current study are available from the corresponding author on reasonable request.

\section{Ethics approval and consent to participate}

The study protocol was approved by the ethics committees of Suzhou Centers for Disease Control and Prevention in accordance with the ethical 
guidelines of the 1975 Declaration of Helsinki. Written informed consents were obtained from the parents of children after declaring the objectives of the present study.

\section{Consent for publication}

Not applicable.

\section{Competing interests}

The authors declare that they have no competing interests.

\section{Author details}

${ }^{1}$ Suzhou Center for Disease Control and Prevention, 72 Sanxiang Road, Suzhou 215000, China. ${ }^{2}$ Gusu Center for Disease Control and Prevention, Suzhou, China. ${ }^{3}$ Department of Epidemiology and Statistics, School of Public Health, Jiangsu Key Laboratory and Translational Medicine for Geriatric Disease, Medical College of Soochow University, 199 Renai Road, Suzhou 215123, Jiangsu, China. ${ }^{4}$ Shanghai Center for Disease Control and Prevention, Shanghai, China.

Received: 16 April 2019 Accepted: 30 June 2019

Published online: 19 July 2019

\section{References}

1. Wiese-Posselt M, Siedler A, Mankertz A, Sauerbrei A, Hengel H, Wichmann O, et al. (2017) Varicella-zoster virus seroprevalence in children and adolescents in the pre-varicella vaccine era, Germany. BMC Infect Dis. 2017; doi: https:// doi.org/10.1186/s12879-017-2461-2.

2. Levin MJ, Weinberg A, Schmid DS. Herpes simplex virus and varicella-zoster virus. Microbiol Spectr. 2016. https://doi.org/10.1128/microbiolspec.DMIH20017-2015.

3. Sauerbrei A. Diagnosis, antiviral therapy, and prophylaxis of varicella-zoster virus infections. Eur J Clin Microbiol Infect Dis. 2016;35:723-34.

4. Manistarski M, Levin D, Dvir R, Berger-Achituv S, Rosenfeld Keidar H, GrisaruSoen $\mathrm{G}$, et al. Lessons from an outbreak of varicella infection in pediatric hematooncology patients. Pediatr Infect Dis J. 2018;37:649-53.

5. Gowin E, Wysocki J, Michalak M. Don't forget how severe varicella can becomplications of varicella in children in a defined polish population. Int J Infect Dis. 2013:17:e485-9.

6. Schots JP, Moons P, Stoot JH. Management of varicella gangrenosa: a lifethreatening condition from chickenpox. Case Rep Med. 2014. https://doi. org/10.1155/2014/206152.

7. Curran D, Schmidt-Ott R, Schutter U, Simon J, Anastassopoulou A, Matthews S. Impact of herpes zoster and postherpetic neuralgia on the quality of life of Germans aged 50 or above. BMC Infect Dis. 2018. https://doi.org/10.1186/ s12879-018-3395-z.

8. Gabutti G, Franchi M, Maniscalco L, Stefanati A. Varicella-Zoster virus: pathogenesis, incidence patterns and vaccination programs. Minerva Pediatr. 2016;68:213-25.

9. Damm O, Witte J, Wetzka S, Prosser C, Braun S, Welte R, et al. Epidemiology and economic burden of measles, mumps, pertussis, and varicella in Germany: a systematic review. Int J Public Health. 2016;61:847-60.

10. Sadaoka T, Mori Y. Vaccine development for varicella-zoster virus. Adv Exp Med Biol. 2018;1045:123-42.

11. Chan DYW, Edmunds WJ, Chan HL, Chan V, Lam YCK, Thomas SL, et al. The changing epidemiology of varicella and herpes zoster in Hong Kong before universal varicella vaccination in 2014. Epidemiol Infect. 2018;146:723-34

12. Helmuth IG, Poulsen A, Suppli CH, Mølbak K. Varicella in Europe-a review of the epidemiology and experience with vaccination. Vaccine. 2015;33:2406-13.

13. Hoshi SL, Kondo M, Okubo I. Cost-effectiveness of varicella vaccine against herpes zoster and post-herpetic neuralgia for elderly in Japan. Vaccine. 2017:35:3264-71.

14. Ma H, Fontaine R. Centers for disease control and prevention (CDC). Varicella outbreak among primary school students--Beijing, China, 2004. MMWR. 2016:55:39-43.

15. Yang Y, Geng X, Liu X, Wang W, Zhang J. Association between the incidence of varicella and meteorological conditions in Jinan, eastern China, 2012-2014. BMC Infect Dis. 2016. https://doi.org/10.1186/s12879-016-1507-1.

16. Fu J, Jiang C, Wang J, Zhao F, Ma T, Shi R, et al. Epidemiology of varicella in Haidian district, Beijing, China-2007-2015. Vaccine. 2017;35:2365-71.
17. Xu Y, Liu S, Che X, Liu Y, Zhang X, Du J, et al. Seroepidemiology of varicella in Hangzhou, China in the vaccine era. Hum Vaccin Immunother. 2018;18:1-8.

18. Hu Y, Chen $Y$, Zhang $B, L i ~ Q$. An evaluation of voluntary varicella vaccination coverage in Zhejiang Province, East China. Int J Environ Res Public Health. 2016. https://doi.org/10.3390/ijerph13060560.

19. Zhang Y, Zang GQ, Tang ZH, Yu YS. Universal varicella vaccination needs to be high on the agenda in China. Rev Inst Med Trop Sao Paulo. 2012;54:237-8.

20. Inoue H, Motani-Saitoh H, Sakurada K, Ikegaya H, Yajima D, Hayakawa M, et al. Determination of the geographical origin of unidentified cadavers based on geographical differences in genotype of varicella-zoster virus. J Med Virol. 2010;82:903-8

21. Kwak BO, Lee HJ, Kang HM, Oh CE, Choi EH. Genotype analysis of ORF 62 identifies varicella-zoster virus infections caused by a vaccine strain in children. Arch Virol. 2017;162:1725-30

22. Oh HS, Bae JM. Vaccination history in elementary school children enrolled in the varicella epidemic investigations held in Jeju-si, Korea in the first half of 2017. Epidemiol Health. 2017. https://doi.org/10.4178/epih.e2017053.

23. Weinberg A, Popmihajlov Z, Schmader KE, Johnson MJ, Caldas Y, Salazar AT, et al. Persistence of varicella-zoster virus cell-mediated immunity after the administration of a second dose of live herpes zoster vaccine. J Infect Dis. 2018. https://doi.org/10.1093/infdis/jiy514.

24. Zhu S, Zeng F, Xia L, He H, Zhang J. Incidence rate of breakthrough varicella observed in healthy children after 1 or 2 doses of varicella vaccine: results from a meta-analysis. Am J Infect Control. 2018. https://doi.org/10.1016/j. ajic.2017.07.029.

25. Su JR, Leroy Z, Lewis PW, Haber P, Marin M, Leung J, et al. Safety of seconddose single-antigen varicella vaccine. Pediatrics. 2017. https://doi.org/1 0.1542/peds.2016-2536.

26. Depledge DP, Gray ER, Kundu S, Cooray S, Poulsen A, Aaby P, et al. Evolution of cocirculating varicella-zoster virus genotypes during a chickenpox outbreak in Guinea-Bissau. J Virol. 2014;88:13936-46.

27. Loparev VN, Gonzalez A, Deleon-Carnes M, Tipples G, Fickenscher H, Torfason EG, et al. Global identification of three major genotypes of varicella-zoster virus: longitudinal clustering and strategies for genotyping. J Virol. 2014;78:8349-58

28. Kim KH, Choi YJ, Song KH, Park WB, Jeon JH, Park SW, et al. Genotype of varicella-zoster virus isolates in South Korea. J Clin Microbiol. 2011;49:1913-6.

29. Sun Z, Guo Y, Li M, Yao Z. Genotype analysis of varicella-zoster virus isolates from suburban Shanghai Municipal Province, China. J Med Microbiol. 2016; $65: 123-8$

\section{Publisher's Note}

Springer Nature remains neutral with regard to jurisdictional claims in published maps and institutional affiliations.

Ready to submit your research? Choose BMC and benefit from:

- fast, convenient online submission

- thorough peer review by experienced researchers in your field

- rapid publication on acceptance

- support for research data, including large and complex data types

- gold Open Access which fosters wider collaboration and increased citations

- maximum visibility for your research: over $100 \mathrm{M}$ website views per year

At BMC, research is always in progress.

Learn more biomedcentral.com/submissions 